\title{
Evaluation of the effect of temperature on the tortional stiffness of active Austenitic and active Martensitic Nickel Titanium arch wires: An In-vitro study
}

\author{
Dr. Thomas John, Dr. Abhishek Bansal
}

\section{Introduction}

The first stage of orthodontic treatment entails leveling and aligning the teeth. These orthodontic applications are served by an arch wire that delivers a force that is low and decrease moderately between the appointments. ${ }^{1}$

The wires used for this first stage should have low modulus of elasticity, high resistance to deformation and wide clinical range.

Since the mid 1960s, the availability of materials used for orthodontic arch wires have markedly increased. Today, not only stainless steel but also chrome cobalt, Nickel-Titanium and B-Titanium wires are used in the field of orthodontics.

Stainless steel wire has higher modulus of elasticity and yield strength and hence requires loops, multiple strands and other modifications to achieve the mechanical objectives of the first stage. ${ }^{2}$

Nickel-Titanium wires is superior for this purpose than stainless steel wire because of its following properties (1) high spring-back, (2) low stiffness, (3) super elasticity and (4) shape memory. Because of its above mentioned properties, NiTi wires are considered as the wire of choice for aligning. ${ }^{3}$

Nickel-Titanium wires are associated with advantages like fewer arch wire changes, less chair side time, reduction in time required to accomplish rotations and leveling, and less patient discomfort.

Nickel-Titanium can exist in more than one structure which are: (1) Stabilized Martensitic, (2) Active austenitic and (3) Active martensitic. The phase of the active NiTi depends on the temperature and mechanical stress to which the alloy is subjected ${ }^{4}$.

Phase transformation can occur either by increasing the temperature or within the defined temperature range by applying stress, thus giving these wires two remarkable properties namely superelasticity and shape memory. ${ }^{4}$

Shape memory is defined as a phenomenon, by which a material memorizes the shape given in one phase at a particular temperature, and returns to that shape when taken through a temperature range.

Superelasticity is a phenomenon where a wire exhibits a low continuous force over a wide range. If stress is induced in the wire, the austenite form is changed to martensite form.

To efficiently use these wires in the clinical situation, the orthodontist needs to be aware of the different properties of these wires. ${ }^{5}$

The term "stiffness" represents the force required to deflect over a unit distance. This is proportional to the modulus of elasticity.

Earlier studies were done to evaluate the effects of high to low temperatures on the torsional stiffness of rectangular NiTi wires. However either the methodology have been incomplete or the results obtained from these studies have been inconclusive. ${ }^{4}$

So this study is being done to comprehensively evaluate the effect of hot and cold temperatures on the torsional stiffness of rectangular active NiTi wires.
Objectives
1. To determine the torsional stiffness of rectangular active austenitic and
2. Martensitic NiTi wires at various hot and cold temperatures.
3. Comparison of torsional stiffness of the NiTi wires of different sizes.

\section{Materials:}

\section{Methodology}

1) Three 0.022" slot standard edgewise brackets of 4mm width (Dynalock, 3M-UNITEK).

2) Geometrical instrument box(Fig.1) 
3) Rectangular active austenitic and active martensitic wires of $0.017 " \mathrm{x} 0.025$ " and $0.019 " \mathrm{x} 0.025$ " dimensions (G.A.C)(Fig. $2 \& 3$ )

4) A sensitive torsion checking instrument

5) Thermocouple for temperature measurement

6) A custom made jig (Fig. 4 to 7 )

7) Hounsfield Universal strength Testing Machine (Fig. 8 and 9).

\section{Method of collection of data:}

The jig was made with three brackets in such a way that all the three brackets slots in it lie in a straight line with an interbracket span of $4.5 \mathrm{~mm}$. The outer two brackets were connected to each other with a crossbar so that they could be rotated in unison. They were rotated manually. When a rectangular wire was passed through all the three brackets, and the crossbar connecting the outer two brackets was rotated, the wire exerted torque on the middle bracket (Fig. 10) which could be measured.

The middle bracket was fixed in the center of a ball bearing so that it could rotate with minimum resistance. A stiff stainless steel lever arm with a length of $50 \mathrm{~mm}$ was attached to the middle bracket. Because of this, when the bracket rotates, the lever arm exerts from at its tip. Provision was made to measure this force with the help of the Hounsfield Universal Strength Testing Machine. To measure the amount of rotational deflection, two pointers were fixed to the rotating crossbar which connects the outer brackets. The degree of rotation was measured against a protractor fixed adjacent to the pointers. The purpose of having two pointers was to avoid parallax error in measurement.

To eliminate the force created by the weight of the lever arm itself at the tip of the arm, a round wire was placed in the bracket slots and the force expressed was noted down. It was reduced from the total force measured during testing of the rectangular wire specimens to arrive at the actual force value.

To measure the torsional stiffness of each specimen of wire, it was placed in the slots of the three brackets.

The whole apparatus is kept in a thermostatically controlled water bath. The temperature of the water bath is controlled by ice and heat liberated by the coil of the water bath, the temperature of the water is monitored by a digital thermometer. Ten samples each of various dimensions are tested. The rectangular wires to be tested are fixed in the brackets and tested for torsion. The force exerted by these wires at different temperatures (i.e., from $2^{0} \mathrm{C}$ to $60^{\circ} \mathrm{C}$ at every $1^{0}$ gradient) for $25^{\circ}$ to $40^{\circ}$ (at every $1^{0}$ gradient) twist are recorded.

\section{Statisticalanalysis:}

The mean and standard deviation of the readings are obtained and compared among different temperatures and also among wires of different dimensions.

These readings were tabulated in $\mathrm{mg}$ units. In order to calculate the torsional stiffness in terms of $\mathrm{N}$ $\mathrm{mm} /$ degree, these $\mathrm{mg}$ values were converted to $\mathrm{Kg}$ by dividing by 1000000 . The obtained values were converted to Newton's using the formula.

$$
\mathrm{X} \mathrm{Kg}=(\mathrm{X} \times 9.80665)
$$

Study shows the comparisons of mean and standard deviation between 0.017 "x 0.025 " and 0.019 "x 0.025 " wires at $37^{\circ} \mathrm{C}$ with increasing twist from 25 to 40 degrees using Students unpaired Test.

Study shows the comparisons of mean and standard deviation between 0.017 "x 0.025 " and 0.019 "x 0.025 " wires at 25 degree of twist with increasing temperature from $2^{0}$ to $60^{\circ} \mathrm{C}$ using Repeated measures ANOVA test.

Student Newman Kuelstest is used to determine any significant difference between two temperatures. Graph 1 shows the amount of force exerted by $0.017 " \mathrm{x} 0.025^{\prime \prime}$ and (blue dots) and 0.019 "x0.025" (pink dots) wires at $37^{\circ} \mathrm{C}$ with increasing twist from 25 to 40 degrees.

Graph 2 and 3 shows $0.017 " x 0.025^{\prime \prime}$ and 0.019 "x $0.025^{\prime \prime}$ wires at $37^{\circ} \mathrm{C}$ with increasing twist from 25 to 40 degrees.

Graph 4, 5, 6, 7 and 8 shows the amount of force exerted by 0.017 "x $0.025^{\prime \prime}$ and $0.019 " \mathrm{x} 0.025^{\prime \prime}$ wires at 25 degree of twist with increasing the temperature from $2^{0}$ to $60^{\circ} \mathrm{C}$.

The results from the study shows that there is a significant difference in the amount of force exerted between $0.017 " \mathrm{x} 0.025^{\prime \prime}$ and $0.019^{\prime \prime} \mathrm{x} 0.025^{\prime \prime}$ wires at $37^{\circ} \mathrm{C}$ with increasing twist from 25 to 40 degrees using Students Unpaired T Test and significant difference in the amount of force exerted between 0.017 " $\mathrm{x} 0.025^{\prime \prime}$ and $0.019 " \mathrm{x} 0.025^{\prime \prime}$ wires at 25 degree of twist with increasing temperature from $2^{0}$ to $60^{\circ} \mathrm{C}$ using Repeated measures ANOVA test.

Student Newman Kuels test shows there is significant difference between two temperatures at 25 degrees of twist. 

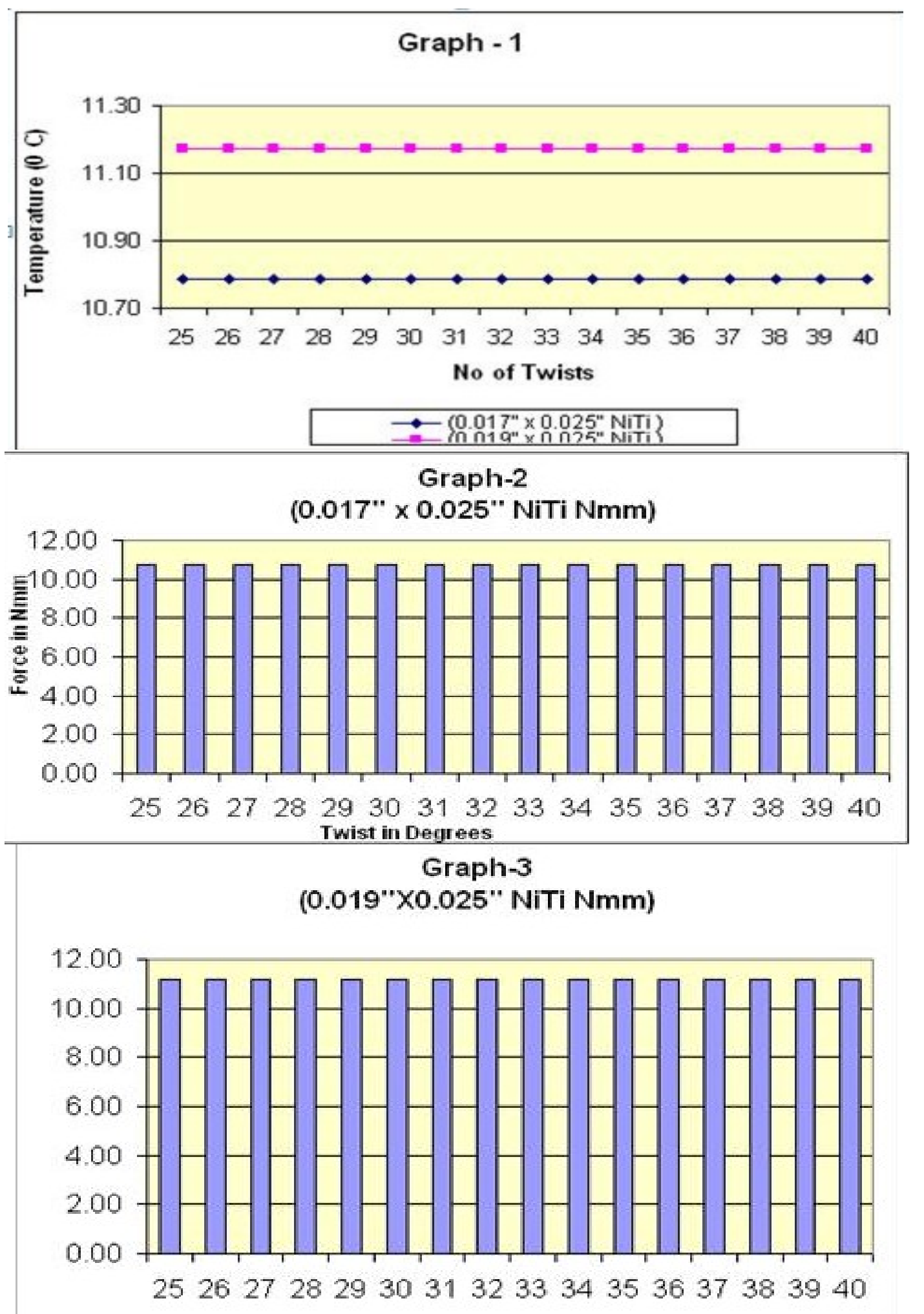


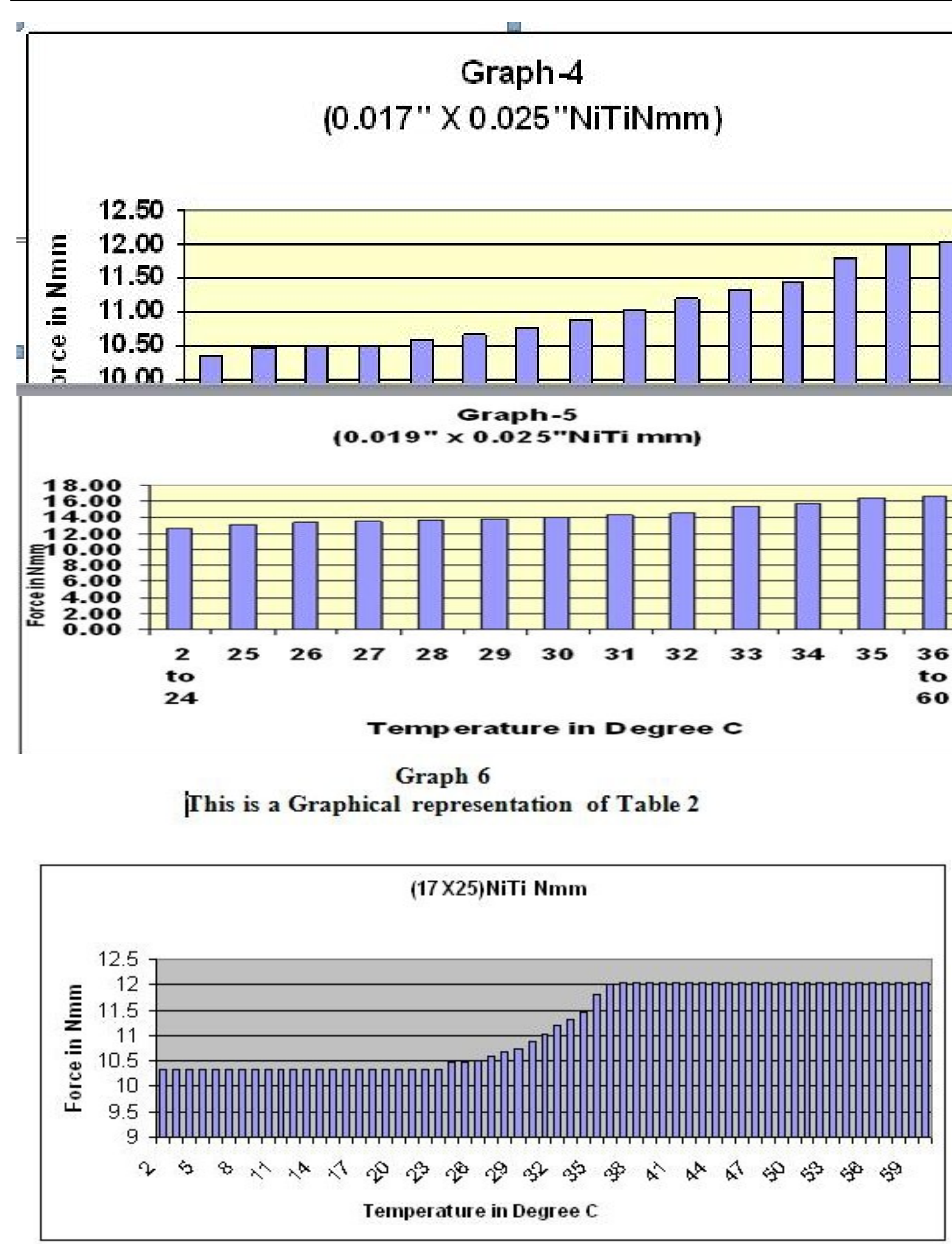


Kraph 7
This is a Graphical representation of Table 2

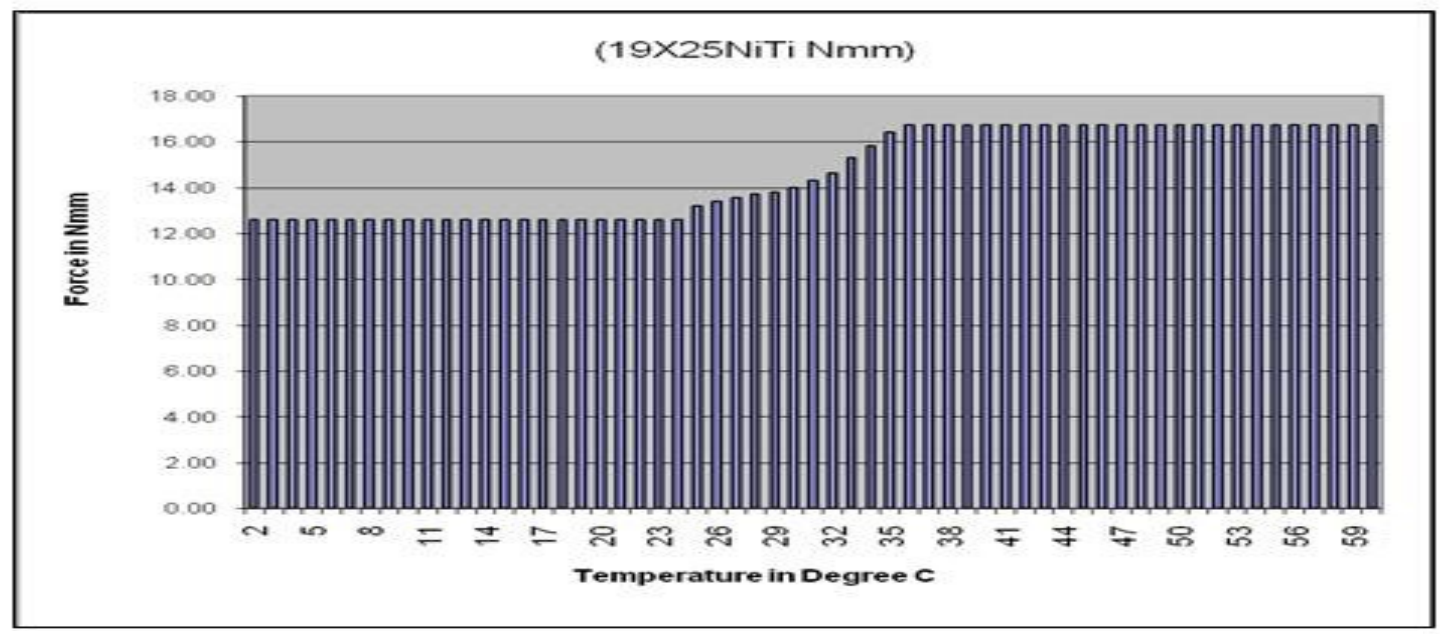

Graph $\mathbf{3}$

This is a Graphical representation of Table 2

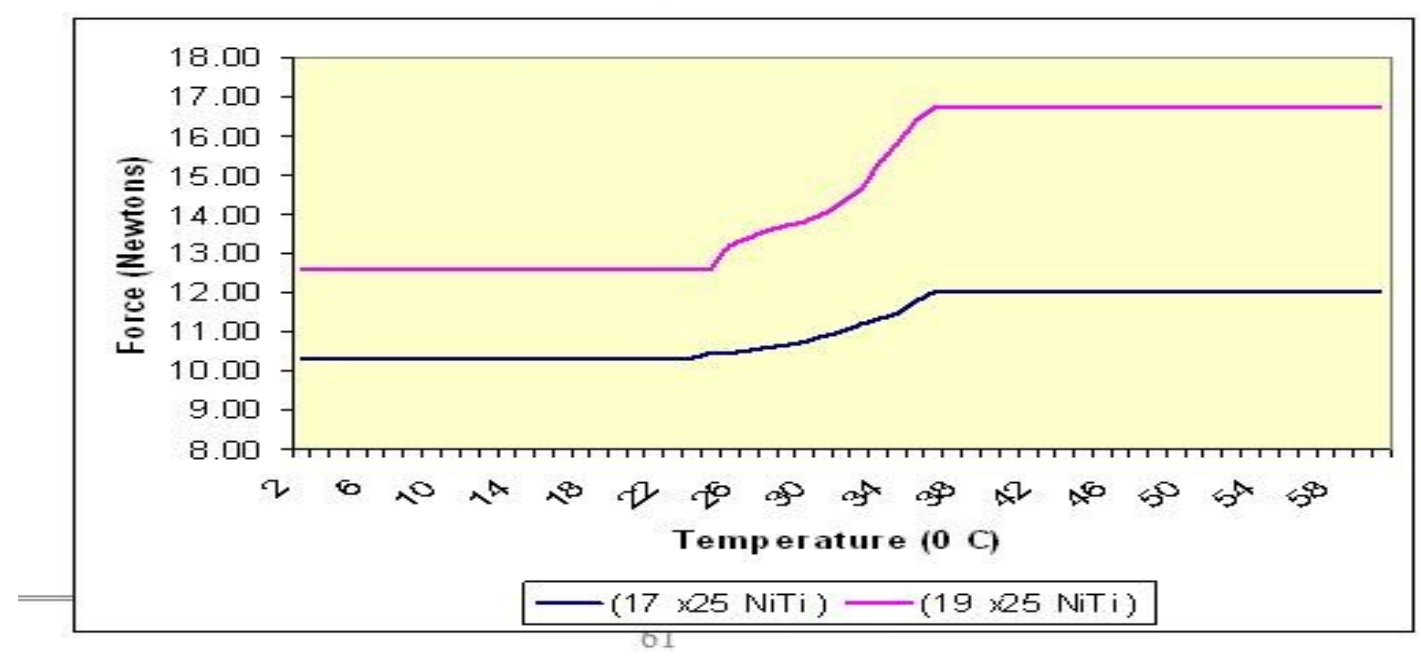

\section{Results}

The present study is designed to evaluate the effect of temperature on the torsional stiffness of rectangular active austenitic and active martensitic Nickel Titanium alloys.

The aim of the present study is to accurately measure the torsional stiffness of different wire alloys of $0.019 " \mathrm{x} 0.025$ " and $0.017 " \mathrm{x} 0.025 "$ dimensions. The wire alloys tested were active austenitic and active martensitic Nickel Titanium alloys.

The study was conducted at different temperatures and twist from $2^{0}$ to $60^{\circ} \mathrm{C}$ temperature at 25 degree of twist and from 25 to 40 degrees of twist at $37^{\circ} \mathrm{C}$ temperature.

The present study showed that the amount of force delivered by the wires, varied with the twist and the amount of temperature to which the wires were subjected.

The amount of torque exerted at 25 degrees of twist from $2^{0}$ to $60^{\circ} \mathrm{C}$ of temperature and from 25 to 40 degrees of twist at $37^{\circ} \mathrm{C}$ varied considerably between $0.017 " \mathrm{x} 0.025^{\prime \prime}$ and $0.019 " \mathrm{x} 0.025^{\prime \prime}$ wires.

All the wires were affected by temperature changes to varying extents and exerted more torque for given amount of twist at higher temperatures.

Study shows the amount of force exerted by $0.017 " \mathrm{x} 0.025^{\prime \prime}$ and 0.019 "x $0.025^{\prime \prime}$ wires at $37^{\circ} \mathrm{C}$ with increasing twist from 25 to 40 degrees.

The amount of force exerted by $0.017 " \mathrm{x} 0.025^{\prime \prime}$ active austenitic wire at $37^{\circ} \mathrm{C}$ at 25 degree of twist is $10.66 \mathrm{Nmm}$ and remained the same with increase in twist from 26 to 40 degrees of twist at the same temperature. 
The amount of force exerted by $0.019 " x 0.025^{\prime \prime}$ active austenitic wire at $37^{\circ} \mathrm{C}$ at 25 degree of twist is $11.16 \mathrm{Nmm}$ and remained the same with increase in twist from 26 to 40 degrees at the same temperature.

Study shows the amount of force exerted by $0.017 " \mathrm{x} 0.025$ " and 0.019 "x 0.025 " wires at 25 degree of twist with increasing temperature from $2^{0}$ to $60^{\circ} \mathrm{C}$.

The amount of force exerted at $2^{0} \mathrm{C}$ at 25 degree of twist $0.017 " \mathrm{x} 0.025 "$ is $10.3 \mathrm{Nmm}$ and remained the same with increase in temperature from $3^{0}$ to $23^{\circ} \mathrm{C}$. At $24^{0} \mathrm{C}$ the force exerted is $10.43 \mathrm{Nmm}$ which indicates that at this temperature the phase transition from austenite to martensite has begun. The amount of force increased with further increase in temperature from $25^{\circ}(10.45)$ to $37^{\circ} \mathrm{C}(11.99)$. The amount of force at $37^{\circ} \mathrm{C}$ is 11.99 and remained the same with further increase in temperature from $38^{\circ}$ to $60^{\circ} \mathrm{C}$ which indicates that the phase transformation is complete at $37^{\circ} \mathrm{C}$ and there was no variation in the force with further increase in temperature.

The amount of force exerted at $2^{0} \mathrm{C}$ at 25 degree of twist by $0.019 " x 0.025 "$ is $12.78 \mathrm{Nmm}$ and remained the same with increase in temperature from $3^{0}$ to $24^{\circ} \mathrm{C}$. At $25^{\circ} \mathrm{C}$ the force exerted is $13.45 \mathrm{Nmm}$ which indicates that at this temperature the phase transition from austenite to martensite has begun. The amount of force increased with further increase in temperature from $26^{\circ}(13.6)$ to $36^{\circ} \mathrm{C}(16.9)$. The amount of force at $36^{\circ} \mathrm{C}$ is 16.9 and remained the same with further increase in temperature from $37^{\circ}$ to $60^{\circ} \mathrm{C}$ which indicates that the phase transformation is complete at $36^{\circ} \mathrm{C}$ and there was no variation in the force with further increase in temperature.

The amount of torque exerted at 25 degrees of twist from $2^{0}$ to $60^{\circ} \mathrm{C}$ of temperature and from 25 to 40 degrees of twist at $37^{\circ} \mathrm{C}$ varied considerably between $0.017 " \mathrm{x} 0.025 "$ and $0.019 " \mathrm{x} 0.025$ " wires and could be attributed to the variation in torsional play and stiffness.

Study shows the comparisons of mean and standard deviation between 0.017 "x 0.025 " and 0.019 "x 0.025 " wires at $37^{0} \mathrm{C}$ with increasing twist from 25 to 40 degrees using Students unpaired Test.

Study shows the comparisons of mean and standard deviation between 0.017 "x 0.025 " and 0.019 "x0.025" wires at 25 degree of twist with increasing temperature from $2^{\circ}$ to $60^{\circ} \mathrm{C}$ using Repeated measures ANOVA test.

\section{Discussion}

During the past few decades, there has been a remarkable increase in the variety of the wires available to orthodontists to meet the clinical needs. When stainless steel was the only material available, the orthodontics were forced to manipulate wire cross-section and length of wire segments to make the material fit different requirements. With the development of chromium-cobalt, nickel-titanium, and rectangular multibraided wires by several different methods of wrapping, 3, 5, 6, 8 or 9 strands of stainless steel, the orthodontists were presented with a wide variety of options. Clinical judgments of the "feel" of a wire can be particularly misleading with wires that have variable relationships among the basic physical properties of strength, stiffness, and range. It also takes a long time to gain clinical experience with the possible applications of so many different wires.

Many orthodontists consider application of a torsional moment as one of the most difficult tasks in orthodontic treatment. Incomplete knowledge of the appropriate degree of twist necessary to deliver a predetermined amount of torsional moment, and variation in the orthodontic appliances has complicated the matter further. Hence, a thorough knowledge about the torsional stiffness would make the orthodontist more efficient and successful. ${ }^{5}$

At this point it is relevant to define some important mechanical terminologies which are enumerated in this study.

Stress - Internal distribution of load - force/ unit area (internal force intensity resisting the applied load).

Strain - Internal distortion produced by the load - deflection/unit length (change in length/original length).

Stiffness - it is the ratio of stress to strain within the elastic limit, and is measured as the force required to deflect a wire through a unit distance.

Resilience (Stored energy) - The capacity of a material to absorb energy, when the material is elastically deformed. Resilience is measured by the area under the elastic portion of the engineering stress-strain curve.

Shape memory - Is defined as a phenomenon by which a material memorizes the shape given in one phase at a particular temperatures, and returns to that shape when taken through a temperature range. ${ }^{3}$ 
Superelasticity - Is defined as a phenomenon where a wire exhibits a low continuous force a wide range. If stress is induced in the wire, the austenite form is changed to martensite form ${ }^{3}$.

The main aim of the present study was to accurately measure the torsional stiffness of different wire alloys of $0.017 " \mathrm{x} 0.025 "$ and $0.019 " \mathrm{x} 0.025 "$ dimension. The wire alloys tested were active austenitic and active martensitic Nickel Titanium alloys.

The present study was conducted at different temperatures and twist from $2^{0}$ to $60^{\circ} \mathrm{C}$ temperatures at 25 degree of twist and from 25 to 40 degrees of twist at $37^{\circ} \mathrm{C}$ temperature. The physical properties of the wires selected for testing do differ significantly at room and mouth temperatures. Since the torsional stiffness of any wire depends on modulus of elasticity, cross section (square/rectangular) and length of the wire, the latter two were kept constant while testing different alloys. During testing different dimensions, only the length was kept constant. The test was conducted on as received condition of the wires.

This study was done using a custom made jig. The jig was designed and fabricated incorporating three standard edgewise brackets with an inter-bracket span of $4.5 \mathrm{~mm}$ simulating the average distance between the brackets on two upper central incisors, and between the central incisor and lateral incisor on any one side.

The provision of rotating the outer two brackets in union which causes the wire to exert moment on the middle bracket also simulates the clinical situation. This design of the jig with three brackets has been used previously by Odegaard ${ }^{5}$ in various experiments on torsional stiffness of stainless steel and nickel-titanium wires.

The present study showed that the amount of force delivered by the wires depend on the twist and the amount of temperature to which the wire is subjected.

The amount of torque exerted at 25 degrees of twist from $2^{0}$ to $60^{\circ} \mathrm{C}$ of temperature and from 25 to 40 degrees of twist at $37^{0} \mathrm{C}$ varied considerably between $0.017 " \mathrm{x} 0.025^{\prime \prime}$ and 0.019 "x $0.025^{\prime \prime}$ wires and this could be attributed to the variation in torsional play and stiffness. ${ }^{6}$

All the wires were affected by temperature changes to varying extents and exerted more torque for given amount of twist at higher temperatures.

The wires exerted the least amount of torque at $2{ }^{\circ} \mathrm{C}$ and highest amount of torque at $37^{\circ} \mathrm{C}$ for $0.017 " \mathrm{x} 0.025^{\prime \prime}$ wire and exerted highest amount of torque at $36^{\circ} \mathrm{C}$ for $0.019^{\prime \prime} \mathrm{x} 0.025^{\prime \prime}$ wire.

The wires exerted same amount of force from 25 to 40 degrees of twist at $37^{\circ} \mathrm{C}$ temperature for both the dimensions.

The results from the study conformed that the amount of twist (from 25 to 40 degrees at $37^{\circ} \mathrm{C}$ temperature) was not sufficient for conversion of austenite to martensite.

The amount of force exerted by $0.017 " \mathrm{x} 0.025^{\prime \prime}$ active austenitic wire at $37^{\circ} \mathrm{C}$ at 25 degree of twist is $10.66 \mathrm{Nmm}$ and remained the same with increase in twist from 26 to 40 degrees of twist at the same temperature. The force remained the same because the amount of twist at that temperature $\left(37^{0} \mathrm{C}\right)$ was insufficient for the conversion of austenite to martensite. These findings are supported by the results of the study done by Meling TR and Odegaard $\mathrm{J}^{4,6}$. In the study by Meling and Odegard, the authors studied the stiffness only a twist of every 5 degrees of gradient. In the present study however the stiffness was measured at every 1 degree gradient.

The amount of force exerted by $0.019 " \mathrm{x} 0.025^{\prime \prime}$ active austenitic wire at $37^{\circ} \mathrm{C}$ of twist is $11.16 \mathrm{Nmm}$ and remained the same with increase in twist from 26 to 40 degrees of twist at the same temperature. The force remained the same because the amount of twist at that temperature $\left(37^{0} \mathrm{C}\right)$ was insufficient for the conversion of austenite to martensite. These findings are supported by the results of the study done by Meling TR and Odegaard $\mathrm{J}^{4,6}$, In the study by Meling and Odegaard, the authors studied the stiffness only a twist of every 5 degrees of gradient. In the present study however the stiffness was measured at every 1 degree gradient.

The amount of force exerted at $2^{0} \mathrm{C}$ at 25 degree of twist by $0.017 " \mathrm{x} 0.025^{\prime \prime}$ is $10.3 \mathrm{Nmm}$ and remained the same with increase in temperature from $3^{0}$ to $23^{\circ} \mathrm{C}$. At $24^{0} \mathrm{C}$ the force exerted is $10.43 \mathrm{Nmm}$ which indicates that at this temperature the phase transition from austenite to martensite has begun to occur. The amount of force increased with further increase in temperature from $25^{\circ}(10.45)$ to $37^{\circ} \mathrm{C}(11.99)$. The amount of force at $37^{\circ} \mathrm{C}$ is 11.99 and remained the same with further increase in temperature from $38^{\circ}$ to $60^{\circ} \mathrm{C}$ which indicates that the phase transformation is complete at $37^{\circ} \mathrm{C}$ and there was no variation in the force with further increase in temperature. These findings are supported by the results of the study done by Iijirna $\mathrm{O}$, Kawashima $\mathrm{I}^{7}$ and Andreasen G, Heilman $\mathrm{H}^{8}$. In the study by Iijirna O, Kawashima I and Andreasen G, Heilman H, the authors studied the temperature at every 5 degrees of gradient. In the present study however the temperature was measured at every 1 degree gradient.

The amount of force exerted at $2^{0} \mathrm{C}$ at 25 degree of twist by $0.017 " \mathrm{x} 0.025^{\prime \prime}$ is $12.78 \mathrm{Nmm}$ and remained the same with increase in temperature from $3^{0}$ to $24^{\circ} \mathrm{C}$. At $25^{\circ} \mathrm{C}$ the force exerted is $13.45 \mathrm{Nmm}$ which indicates that at this temperature the phase transition from austenite to martensite has begun to occur. The amount of force increased with further increase in temperature from $26^{\circ}(13.6)$ to $36^{\circ} \mathrm{C}(16.9)$. The amount of force at $36^{\circ} \mathrm{C}$ is 
16.9 and remained the same with further increase in temperature from $37^{\circ} \mathrm{C}$ to $60^{\circ} \mathrm{C}$ which indicates that the phase transformation is complete at $36^{\circ} \mathrm{C}$ and there was no variation in the force with further increase in temperature. These findings are supported by the results of the study done by Iijirna $\mathrm{O}$, Kawashima $\mathrm{I}^{7}$ and Andreasen G, Heilman $\mathrm{H}^{8}$. In the study by Iijirna O, Kawashima I and Andreasen G, Heilman H, the authors studied the temperature at every 5 degrees of gradient. In the present study however the temperature was measured at every 1 degree gradient.

The amount of force exerted by $0.017 " x 0.025^{\prime \prime}$ active austenitic Nickel Titanium wire at $37^{0} \mathrm{C}$ with increase in twist from 25 to 40 degrees remained the same (10.66 Nmm). This was because the amount of twist at that temperature $\left(37^{0} \mathrm{C}\right)$ was insufficient for the conversion of austenite to martensite. Further increase in twist ( $>40$ degree) was not done because of the limitations of the jig.

The amount of torque exerted at 25 degree of twist from $2^{0}$ to $60^{\circ} \mathrm{C}$ of temperature and from 25 to 40 degrees of twist at $37^{0} \mathrm{C}$ varied considerably between $0.017 " \mathrm{x} 0.025^{\prime \prime}$ and 0.019 "x $0.025^{\prime \prime}$ wires and this could be attributed to the variation in torsional play and stiffness.

There was considerable difference between $0.017 " \mathrm{x} 0.025$ " and $0.019 " \mathrm{x} 0.025$ " active martensitic Nickel Titanium arch wires, with respect to the temperature at which phase transformation had begun. The phase transformation for $0.017 " \mathrm{x} 0.025^{\prime \prime}$ had begun at $24^{0} \mathrm{C}$. The phase transformation for $0.019 " \mathrm{x} 0.025^{\prime \prime}$ had begun at $25^{\circ} \mathrm{C}$.

This variation in temperature of the phase change between these two dimensions could be attributed to either manufacturing defect or differences in compositions between the two dimensions.

In a clinical situation where major leveling and aligning has been completed with round wires, the third order deflection between the teeth would most likely be less than 40 degrees. The results from this study indicate that in such a situation, the rectangular active austenitic NiTi wire would be not effective because the amount of deflection would be not sufficient to initiate the phase transformation to martensite.

\section{Conclusion}

When two different NiTi (active austenitic and active martensitic) wires of two different dimensions (0.017"x 0.025 " and 0.019 "x 0.025 ") were investigated for torsional stiffness at different degree of twist and at different temperatures the following conclusions were made;

1. The amount of twist (from 25 to 40 degrees at a constant temperature of $37^{\circ} \mathrm{C}$ ) was not sufficient for active austenitic wire to exhibit its superelasticity property. The amount of twist should be increased until the phase transformation of austenite to martensite has occurred or the temperature should be decreased to exhibit its superelasticity.

Hence the study confirms that the active austenitic wire is not the wire of choice in a clinical situation where, the deflection between the teeth is less than 40 degrees and third order control is required.

In such a situation either active martensitic or conventional NiTi would be beneficial both in terms of the amount of force the wire delivers and to correct the deflection.

The active austenitic Nickel Titanium wire would be not effective because the amount of deflection was not sufficient for the austenite to get converted to martensite.

On engaging such a wire would be deleterious to the teeth and the investing tissue because of its heavy forces.

2. The amount of temperature (from $2^{0} \mathrm{C}$ to $60^{\circ} \mathrm{C}$ at 25 degree of twist) was sufficient to exhibit its shape memory property. The wires (active martensitic) were flexible at room temperature and became stiffer as the temperature was increased till $37^{\circ} \mathrm{C}$ thereafter the force remained constant with further increase in temperature. Hence the active martensitic wire can be used in malocclusions which exhibits significant amount of deflection.

\section{Bibliography}

[1]. Waters NE. Superelastic nickel-titanium wires. Br J Orthod 1992; T9: 319-322.

[2]. Kapila S and Sachdeva R. Mechanical properties and clinical applications of orthodontic wires. Am J OrthodDentofacOrthop 1989; 96: 100-109

[3]. Meling TR, Odegaard J and Meling EO. On mechanical properties of square and rectangular stainless steel wires tested in torsion. Am J OrthodDentofacOrthop 1997; 111:310-320.

[4]. Meling TR and Odegaard J. The effect of short term temperature changes on the mechanical properties of rectangular nickel titanium archwires tested in torsion. Angle Orthod 1998; 68: 369-376.

[5]. Meling TR and Odegaard J. On the variability of cross sectional dimensions and torsional properties of rectangular nickel-titanium arch wires. Am J OrthodDentofacOrthop 1998; 113: 546-557

[6]. Meling TR and Odegaard J. The effect of temperature on the elastic response to longitudinal torsion of rectangular nickel titanium archwires. Angle Orthod 1998; 68: 357-368.

[7]. Iijira M, Ohno H, Kawashima I, Endo K and Mizoguchi I. Mechanical behavior at different temperature and stresses for superelastic nickel-titanium orthodontic wires having different transformation temperatures. Dental Materials 2002; 18: 88-93.

[8]. Andreasen G, Heilman H and Krell D. Stiffness changes in thermodynamic nitinol with increasing temperature. Angle Orthod 1985; 55: $120-126$. 